\title{
Experimental investigation of evaporation dynamic of sessile droplets in pure vapor environment with low pressures
}

\author{
Shuang Ye ${ }^{\mathrm{a}}$, Li Zhang ${ }^{\mathrm{b}}$, Chun-Mei Wu ${ }^{\text {a }}$, You-Rong $\mathrm{Li}^{\mathrm{a}}{ }^{\text {,* }}$, Qiu-Sheng Liu ${ }^{\mathrm{c}}$ \\ ${ }^{a}$ Key Laboratory of Low-grade Energy Utilization Technologies and Systems of Ministry of Education, College of Power Engineering, Chongqing University, Chongqing \\ 400044, China \\ b Chongqing City Management College, Chongqing 401331, China \\ ${ }^{\mathrm{c}}$ Key Laboratory of Microgravity (National Microgravity Laboratory), Institute of Mechanics, Chinese Academy of Sciences, Beijing, 100190, China
}

\section{A R T I C L E I N F O}

\section{Keywords:}

Sessile droplet

Evaporation

Pure vapor

Low pressure

Experiment

\begin{abstract}
A B S T R A C T
In order to understand the evaporation dynamic of sessile droplet in pure vapor environment, this paper presented a series of experimental observations on the evolution of thermal patterns and the variation of evaporation rate during water and ethanol droplet evaporation at low pressures. The contact radius of droplet is fixed at $2.5 \mathrm{~mm}$ and the height varies from 0.4 to $1.6 \mathrm{~mm}$. Results show that the surface temperature distributions for both water and ethanol are uniform at a high pressure ratio. When the pressure is reduced, a ring-like thermal pattern appears on the water droplet surface, while the gear-like pattern and the cellular flow happen on the ethanol droplet surface. Interestingly, the gear-like pattern is static when the substrate temperature is low, while it will oscillate at a high substrate temperature. Meanwhile, the cellular flow is affected by the droplet height. The evaporation is promoted by reducing the pressure. Moreover, due to the decrease of the evaporation surface area and the increase of surface temperature, the evaporation rate decreases first and then increases with the decrease of the droplet height.
\end{abstract}

\section{Introduction}

The evaporation of sessile droplet is a ubiquitous natural occurrence [1], and there are numerous industrial applications, such as spray cooling [2,3], DNA mapping [4,5], surface coating [6,7], inject printing $[8,9]$ and biological and medical diagnosis technologies [10,11]. Moreover, the droplet evaporation is a complex problem involving liquid flow, heat and mass transfer, and phase change, etc. It is precisely because of the complexity and importance of sessile droplet evaporation, more and more attention has been paid to it in the past few decades.

In general, the complex flow in an evaporating sessile droplet will affect the surface evaporation, as well as the particle assembling in a droplet. Numerous studies focus on the internal flow of evaporating sessile droplets that have been reported. In 1997, Deegan et al. [1] studied the coffee-ring phenomenon during the droplet evaporation. They pointed out that for a sessile droplet with pinning contact line, the highest evaporation mass flux near the droplet edge may cause an outward supplementary flow. It is the flow that makes the particles in the droplet deposit near the contact line. Finally, 'coffee-ring' will be formed. Because the temperature is the highest at the contact line, the liquid molecule can escape from the droplet at the contact line region more easily, which results in the appearance of the maximum evaporation mass flux near the contact line $[12,13]$. Except for the flow induced by nonuniform liquid evaporation on the droplet surface, the thermal flow inside the droplet also affects the assembling process a lot. Actually, during the sessile droplet evaporation, both the tangential temperature gradient on the droplet surface and the normal temperature gradient inside the droplet coexist because of the curved gas-liquid interface and the evaporative cooling effect. Due to the temperature dependence of surface tension and density of the liquid, the existence of the temperature gradients may cause a series of thermal flows, such as thermocapillary convection and buoyancy flow. In the report of $\mathrm{Hu}$ and Larson [14], they confirmed that the Marangoni flow exists in an evaporating water droplet and it would restrain the particle assembling near the three-phase contact line. Nowadays, the thermal flow inside an evaporating sessile droplet, as well as its effect on evaporation, has been investigated a lot. Interestingly, the thermal flow is affected by many factors, including the liquid properties, substrate properties, evaporation modes, gas phase conditions et al. In fact, in the sessile droplets containing with different volatile liquids, various thermal patterns induced by thermal flow have been found, including hydrothermal

\footnotetext{
* Corresponding author.

E-mail address: liyourong@cqu.edu.cn (Y.-R. Li).
} 


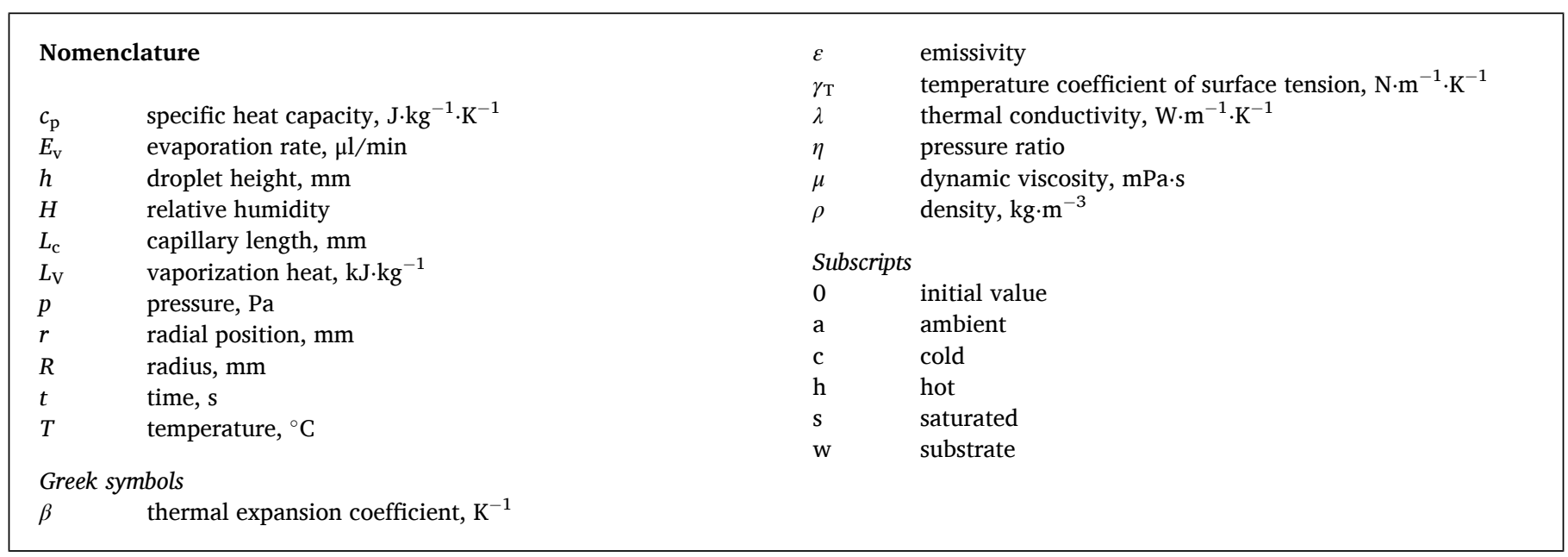

waves and cellular structure waves et al. [15,16]. Using infrared image technology, Sefiane and coworkers $[15,17]$ experimentally investigated sessile droplet evaporation on a heated substrate. It was found that hydrothermal waves exist on the free surface of ethanol and methanol droplet, which is also reported by Sobac and Brutin [18,19]. Moreover, they pointed out that the Nusselt number is constant at 1.7, which proved that both conduction and convection are essential for energy transport. Sefiane et al. [20] confirmed that hydrothermal waves in evaporating droplets are bulk waves. Thermal patterns would influence the evaporation rate. According to the experimental results of Fukatani et al. [21], the evaporation mass flux becomes uniform due to the existence of hydrothermal waves. Although the thermal flow also happened in the evaporating water droplet with the poor volatility [22, 23], the previous reports about the thermal pattern on evaporating water droplets are confusing. Some researchers pointed out that the thermal pattern is difficult to be observed in an evaporating water droplet $[14,15,24]$. On the other hand, the thermal pattern with the stable recirculatory vortices has been found on the evaporating water droplet surface in the work of Josyula et al. [25] and Chen et al. [26].

There are several evaporating modes when the droplet contact line is not pinned. According to the report of Picknett and Bexon [27], two evaporation modes were presented, i.e., the constant contact radius (CCR) mode and the constant contact angle (CCA) mode. Furthermore, a mixed evaporation mode is also proposed [28,29]. During the mixed evaporation mode, the contact angle and the contact radius are simultaneously reduced. Actually, either the change of contact line or contact angle may affect the thermal flow as well as the evaporation. According to the work of Peadhan and Panigrahi [23], the direction of the thermocapillary flow will change with the change of droplet size. Bouchenna et al. [30] numerically simulated the evaporation process of a water droplet on a heated substrate and found that the thermocapillary flow direction will reverse at a low contact angle. It was also pointed out that the evaporation rate is affected by the flow at a large contact angle. Meanwhile, Semenov [31] found that the evaporation flux increases with the decrease of sessile water droplet volume.

The gas condition is another important factor that affects the sessile droplet evaporation. Some studies have been conducted under controlled gas conditions. Fukatani et al. [32] experimentally studied the thermal patterns on evaporating ethanol droplets using infrared camera. They found that regular waves appear at low relative humidity and high ambient temperature. However, the surface temperature distribution becomes uniform when relative humidity increases and/or ambient temperature decreases. It has been found that the surface temperature and the evaporation rate will be affected by the gas convection $[33,34]$. Ghasemi and Ward et al. $[35,36]$ conducted an experiment to study the steady state evaporation of sessile water droplet on $\mathrm{Cu}$ substrate at low pressures. The temperature in droplet and vapor phase is measured by U-shaped thermocouple. The results show that thermocapillary flow will contribute to energy transport during droplet evaporation. Similar conclusions have also been proposed by Mahmud and MacDonald [37]. However, according to Thompson and his coworkers [38], the thermocapillary flow is absent when water evaporates into its vapor in a polymethyl methacrylate funnel substrate. They found that the energy transport from the liquid and the vapor phase is sufficient for droplet evaporation without thermocapillary flow. Recently, using a three-dimensional simulation method, Zhang and coworkers [39] investigate the evaporation of sessile water droplet in its vapor at reduced pressure. Several flow patterns emerge on the droplet surface. Moreover, the total evaporation rate is found to be depended non-monotonically on contact angle. It is worth mentioning that the researches about sessile droplet evaporation are well-reviewed by Erbil [40], Brutin and Starov [41].

Above all, many researches certified that thermal flows exist in the evaporation process of sessile water and ethanol droplet. Furthermore, some reports indicate that thermal flow will affect the evaporation process and the energy transport. However, most of the previous researches are carried out under the atmospheric environment. It should also be noted that there still seems to be some confusion. For instance, whether the thermal pattern exists in an evaporating sessile water droplet surface is contentious. Furthermore, thermal pattern evolution of an evaporating droplet in its pure vapor at low pressures has never been observed experimentally before. This paper presents a series of experiments on the evolution of thermal patterns during steady-state evaporation of sessile water and ethanol droplet in its pure vapor at low pressures. Meanwhile, the influence of thermal flow on evaporation rate is also discussed.

\section{Experimental apparatus}

The experimental apparatus for sessile droplet evaporation in its pure vapor at low pressure is illustrated in Fig. 1. A sealed stainless steel chamber is designed for the purpose of studying the sessile droplet evaporation process in its vapor at low pressures. The geometry of the chamber is $155 \mathrm{~mm} \times 155 \mathrm{~mm} \times 155 \mathrm{~mm}$. In order to observe the droplet morphology, three quartz glass windows are mounted on the left, right, and front sides of the chamber, respectively. To monitor the droplet side view, a CMOS camera (PixeLINK, PL-B771, resolution: 800 $\times 600$ ) is mounted on the left side of the chamber. Accordingly, a planar LED industrial visual light source for a backlight of the COMS camera is mounted on the right side. Based on the side view of droplet morphology caught by CMOS camera, an open source software ImageJ (Image Processing and Analysis in Java) can be used to measure the droplet height 


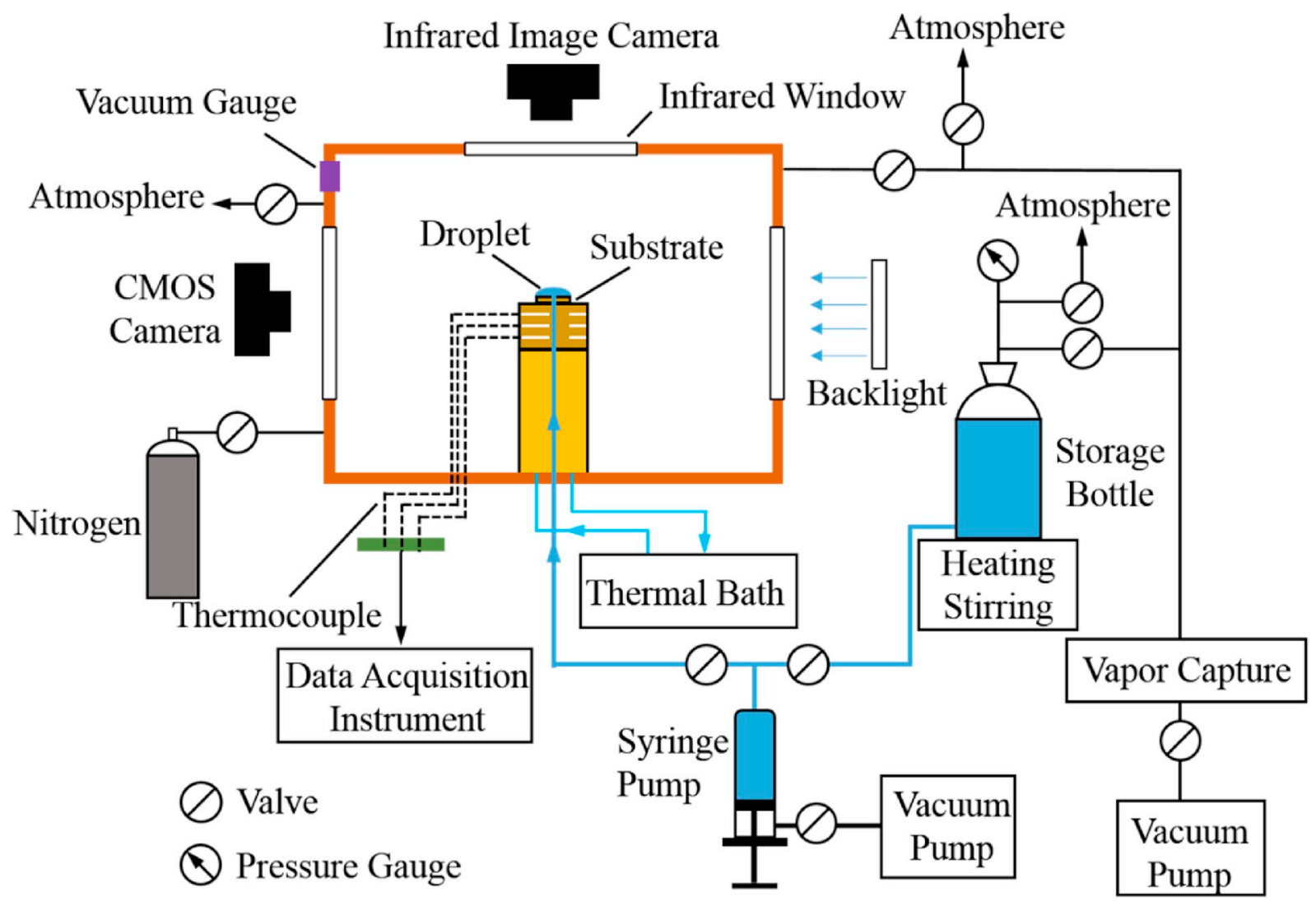

Fig. 1. The schematics of the experimental apparatus.

[42]. During experiments, an infrared image camera with a $25 \mu \mathrm{m}$ macro lens (FLIR SC325, resolution: $320 \times 240$, the field of view: $8 \times 6 \mathrm{~mm}$, heat sensitivity: $0.05{ }^{\circ} \mathrm{C}$ ) is used to measure the temperature distribution on the droplet surface. It is vertically installed above the substrate. Thus, an infrared window that is made of Germanium glass is mounted on the top side of the chamber to ensure the effectiveness of using an infrared camera. It is worth mentioning that the effect of the curved surface on the accuracy of infrared temperature measurement is very small because the droplet height is low. Therefore, the infrared temperature measurement is used in order to display the thermal pattern on droplet surface.

A vacuum pump (Edwards E2M1.5, pumping speed: $1.6 \mathrm{~m}^{3} / \mathrm{h}$, ultimate vacuum: $0.3 \mathrm{~Pa}$ ) is used to maintain the low-pressure state of the chamber. To monitor the pressure of the sealed chamber, a high precision vacuum gauge (INFICON CDG 025D, measurement range: $1.33 \times$
$10^{1}-1.33 \times 10^{5} \mathrm{~Pa}$, accuracy: $0.20 \%$ of reading) is installed on it. By connecting the vacuum gauge to a multi-channel data acquisition instrument (Keysight Technologies, 34972A), the pressure of the test chamber can be monitored in real time. The leak rate of the evaporation chamber is below $1.5 \mathrm{~Pa} / \mathrm{min}$. Before every experiment, the vacuum pump is used to continually evacuate the chamber for more than $6 \mathrm{~h}$ to remove impurities other than droplet vapor.

The cylindrical substrate is the same as the substrate used in the previous report [16]. The side view and surface infrared imaging map of the small substrate is shown in Fig. 2. The small substrate is glued together with a base substrate. Moreover, the thickness and the radius of the small substrate are $\delta=0.5 \pm 0.05 \mathrm{~mm}$ and $R=2.5 \pm 0.05 \mathrm{~mm}$, respectively. In the center of the small substrate, there is a hole with the radius of $0.3 \pm 0.05 \mathrm{~mm}$ for the liquid supplement. Moreover, both the small substrate and the base substrate are made of copper. Before the
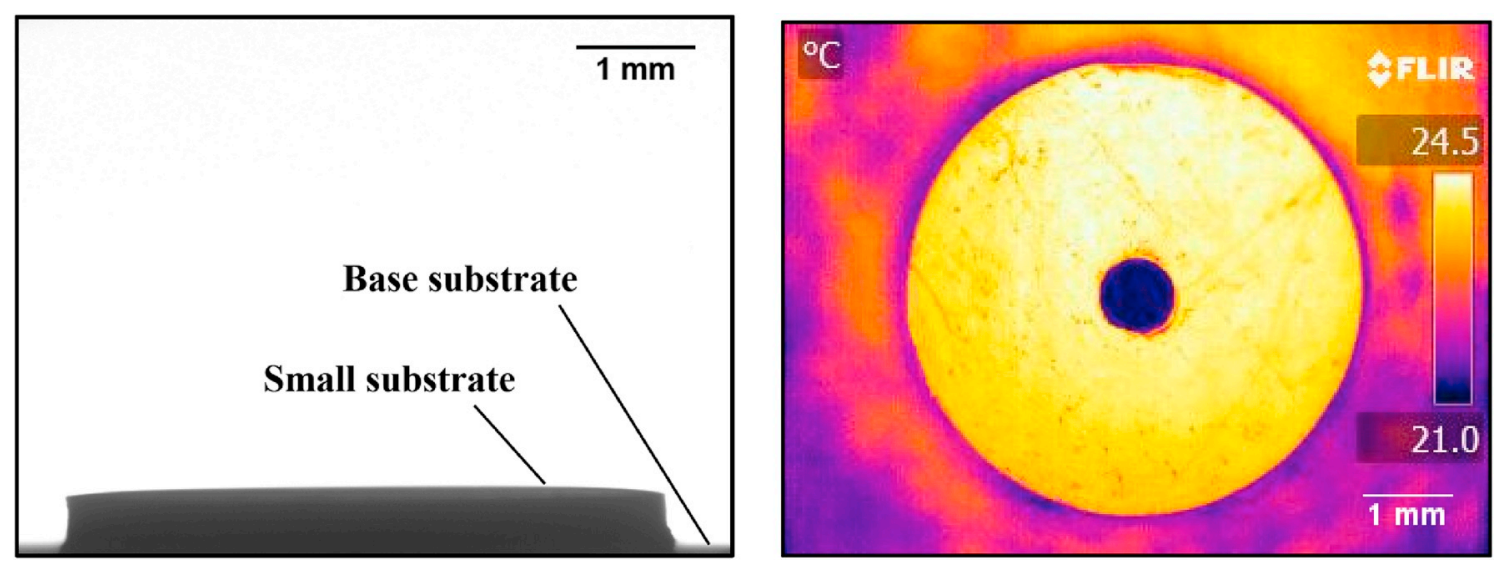

Fig. 2. The side view (left) and surface infrared imaging map (right) of the small substrate. 
droplet formation, a thermostatic water bath (Shanghai Qiqian Electronic Technology Co. Ltd, DC-2006, temperature ranges from $-20^{\circ} \mathrm{C}$ to $100{ }^{\circ} \mathrm{C}$, and the accuracy is $\pm 0.05^{\circ} \mathrm{C}$ ) is used to maintain the substrate temperature. Furthermore, the substrate temperature is measured by 12 K-type thermocouples, which are uniformly mounted in the base substrate. All the temperature data are real-time monitored by the data acquisition instrument.

It is worth mentioning that the gaseous impurities of the experimental liquid in the storage bottle are exhausted with the help of the vacuum pump. Accompanied by a heating and stirring process, the exhausting process lasts at least $6 \mathrm{~h}$ until there is no bubble formation. Then the liquid is filled into a syringe without contacting with air. Using a syringe pump (KDS 200 series), the degassed liquid can be continuously supplied to the small substrate to form a sessile droplet. When the droplet is maintained in steady state evaporation, the evaporation rate is equal to the syringe rate. In this work, pure water and ethanol are used as the experimental liquids. Both of them are supplied by Chongqing Chuandong Co. Ltd. The purity of ethanol is higher than $99.7 \%$. Table 1 shows the physical properties of the experimental liquids at $25{ }^{\circ} \mathrm{C}$. During the experiments, steady-state evaporation is sought by adjusting the pumping rate of the syringe pump and the evacuated rate of the vacuum pump. Within $15 \mathrm{~min}$, if the variation of droplet height is no more than $45 \mu \mathrm{m}$ and the change of vapor pressure is no more than 26.6 $\mathrm{Pa}$, the droplet evaporation is considered to be a steady state. Then the experimental data can be collected, including the evaporation rate, infrared images of the droplet surface, etc.

\section{Experimental results and discussion}

In all experiments, the droplet contact radius is fixed at $R=2.5 \mathrm{~mm}$, which is equal to the radius of the small substrate. To understand the influence of ambient pressure on droplet evaporation at different substrate temperatures, different ambient pressures were set in the experiment. In order to describe the evaporation ambient pressure, the pressure ratio $\eta$ of vapor is introduced, which is defined as the ratio of real pressure in the sealed chamber to the saturation vapor pressure at the substrate temperature. Antoine equation is used to calculate the saturation pressure $P_{\mathrm{s}}$ [46].

$\log _{10} P_{s}=A-B /(T+C)$

where units of $P_{\mathrm{s}}$ and $T$ are $\mathrm{mmHg}$ and ${ }^{\circ} \mathrm{C}$, respectively. $A, B$ and $C$ are Antoine coefficients. For water, $A=8.05573, B=1723.6425$ and $C=$ 233.08 in the temperature range of from 0.01 to $373.98^{\circ} \mathrm{C}$; For ethanol, $A=8.12875, B=1660.8713$ and $C=238.131$ in the temperature range of from -5.15 to $240.75{ }^{\circ} \mathrm{C}$ [47]. Two pressure conditions are set in this work, i.e., $\eta=0.9$ and 0.6 .

When pure water droplet evaporates in its vapor at $T_{\mathrm{w}}=25^{\circ} \mathrm{C}$ and $\eta$ $=0.9$, the side view and infrared images are shown in Fig. 3. As shown in Fig. 3(a), the droplet height is defined as the distance between the small substrate surface and the droplet apex. The infrared images show that

Table 1

Physical properties of water and ethanol at $25^{\circ} \mathrm{C}$ and $1 \mathrm{~atm}$.

\begin{tabular}{lll}
\hline & Water [19] & Ethanol [19] \\
\hline Boiling point $\left({ }^{\circ} \mathrm{C}\right)$ & 100 & 78.0 \\
Density, $\rho\left(\mathrm{kg} \cdot \mathrm{m}^{-3}\right)$ & 997 & 789 \\
Dynamic viscosity, $\mu(\mathrm{mPa} \cdot \mathrm{s})$ & 0.890 & 1.095 \\
Vaporization heat, $L_{\mathrm{V}}\left(\mathrm{kJ} \cdot \mathrm{kg}^{-1}\right)$ & 2449 & 923 \\
Specific heat capacity, $C_{\mathrm{p}}\left(\mathrm{J} \cdot \mathrm{kg}^{-1} \cdot \mathrm{K}^{-1}\right)$ & 4180 & 2845 \\
Thermal conductivity, $\lambda\left(\mathrm{W} \cdot \mathrm{m}^{-1} \cdot \mathrm{K}^{-1}\right)$ & 0.606 & 0.140 \\
Capillary length, $L_{\mathrm{c}}(\mathrm{mm})$ & 2.73 & 1.69 \\
Thermal expansion coefficient, $\beta\left(\mathrm{K}^{-1}\right)$ & $2.56 \times 10^{-4}$ & $1.08 \times 10^{-3}$ \\
& {$[43]$} & {$[44]$} \\
Surface tension temperature coefficient, $\gamma_{\mathrm{T}}$ & $-1.68 \times 10^{-4}$ & $-0.83 \times 10^{-4}$ \\
$\left(\mathrm{~N} \cdot \mathrm{m}^{-1} \cdot \mathrm{K}^{-1}\right)$ & {$[17]$} & {$[17]$} \\
Emissivity, $\varepsilon(-)$ & $0.96[45]$ & $0.92[45]$ \\
\hline
\end{tabular}

the temperature seems to be homogeneous on most droplet surface, while a temperature gradient exists in the region near the three-phase contact line. Moreover, the temperature distribution does not seem to vary with the droplet height.

To confirm that the temperature gradient exists in the contact line region, the tangential temperature distribution along the droplet surface is analyzed. First of all, the three-phase contact line should be accurately determined. As presented in Fig. 4(a), through the relationship between the diameter of the small substrate and the field of infrared imaging view, the position of the three-phase contact line can be accurately found. The red dash circle in Fig. 4(a) is the position of the three-contact line. Fig. 4(b) shows the temperature distribution along the droplet surface obtained at line 1 that is also shown in Fig. 4(a). According to the temperature distribution curve, it is obvious that the surface temperature rises sharply near the three-phase contact line region. Furthermore, when water droplet evaporates at $T_{\mathrm{w}}=20^{\circ} \mathrm{C}$ and $\eta=0.9$, the surface temperature distribution is similar to that at $T_{\mathrm{w}}=25{ }^{\circ} \mathrm{C}$ and $\eta=0.9$.

The evaporation of water droplet at $\eta=0.9$ seems similar to some previous reports, in which no thermal patterns exist on the evaporating water droplet surface [15,21,48,49]. In Ref. [48], a water droplet is deposited on a heated copper substrate with a temperature of $T_{\mathrm{w}}=60$ ${ }^{\circ} \mathrm{C}$. The infrared image shows that temperature difference exists in the latitudinal direction. However, unlike the surface temperature distribution of water droplet at $\eta=0.9$, the surface temperature rises gradually from the droplet apex to the contact line. The authors do not explain why there is no thermal patterns on the water droplet surface. Although some researchers pointed out that the surfactant will suppress the thermocapillary flow [14,50,51], which may be the reason for the thermal patterns to be observed difficultly. Kazemi et al. [52] carried out experimental and numerical studies about water with concave interface evaporating into its vapor. It was found that the thermocapillary flow does not happen. They also attributed the reason for the absence of thermocapillary flow to the surfactant. However, since pure water is used and the steam is the only gas component in the test chamber, there is no surfactant in present work. Thus, it is not the result of surfactant contamination that no thermal patterns emerged on water droplet surface at $\eta=0.9$. It is worth mentioning that, according to numerical simulation [39], when water droplet evaporates into its vapor at $\eta=$ 0.94 and $T_{\mathrm{w}}=25^{\circ} \mathrm{C}$, the obvious temperature gradient only exists in the region near the three-phase contact line. In other words, the numerical result about the surface temperature distribution of evaporating water droplet at low pressures is in accordance with the present experimental result.

Interestingly, when $\eta=0.9$, the surface temperature distributions for ethanol droplets evaporating at $T_{\mathrm{W}}=25^{\circ} \mathrm{C}$ and $20^{\circ} \mathrm{C}$ are also similar to those for pure water droplet evaporating. As exhibited in Fig. 5, the infrared images of ethanol droplet show that the surface temperature is homogeneous. Meanwhile, with the change of droplet height, the temperature distribution does not change a lot.

There are many references that reported the existence of the hydrothermal waves during sessile ethanol droplet evaporating in an atmospheric environment $[18,19,53]$. We also carried out the experiment on the evaporation of ethanol droplet at $T_{\mathrm{w}}=20^{\circ} \mathrm{C}$ in open air condition. The ambient temperature $T_{\mathrm{a}}$ is $25.0^{\circ} \mathrm{C} \pm 1.0^{\circ} \mathrm{C}$, and the relative humidity $H$ of air is $65 \% \pm 5 \%$. Due to the low substrate temperature, no obvious hydrothermal waves appear on the ethanol droplet surface. However, it can be found that the surface temperature distribution is not uniform at $T_{\mathrm{w}}=20{ }^{\circ} \mathrm{C}$ and $h=0.6 \mathrm{~mm}$, as shown in Fig. 6 where the radius of Line 1 is $1.25 \mathrm{~mm}$. Obviously, the surface temperature fluctuates along the longitudinal direction. When ethanol droplet evaporates in the open air, because of the existence of the curved interface, the thermal-conduction resistance between the substrate and the droplet surface is nonuniform. Meanwhile, the evaporation cooling effect may cause temperature disturbances along the longitudinal direction. Thus, the temperature distributions along both the longitudinal and latitudinal directions are not uniform. As a result, thermocapillary flow along the 



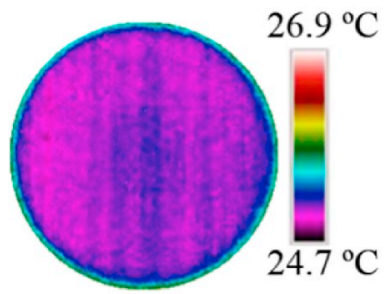

(a) $h=1.6 \mathrm{~mm}$

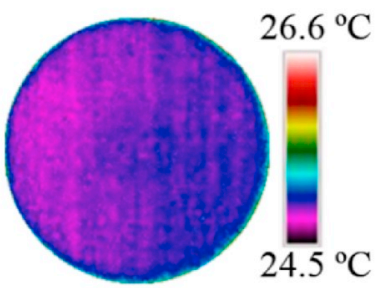

(b) $h=1.2 \mathrm{~mm}$

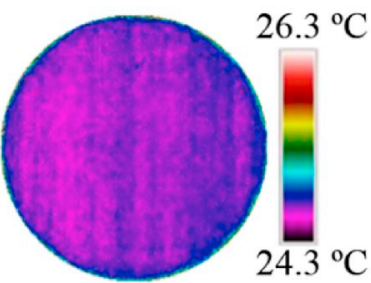

(c) $h=0.8 \mathrm{~mm}$



(d) $h=0.4 \mathrm{~mm}$

Fig. 3. The side view and top infrared images of a water droplet at $T_{\mathrm{w}}=25^{\circ} \mathrm{C}$ and $\eta=0.9$.
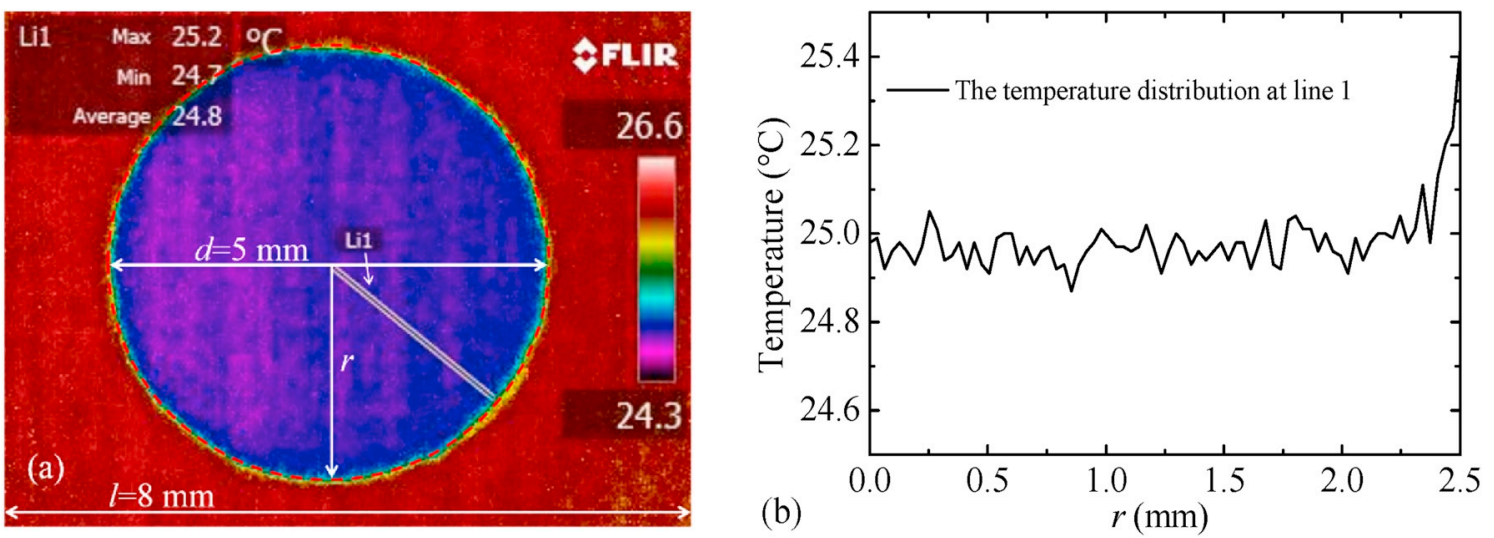

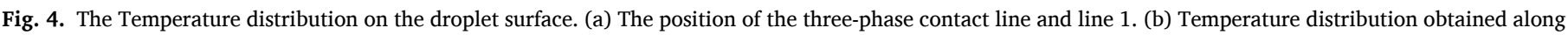
line 1 at $T_{\mathrm{w}}=25{ }^{\circ} \mathrm{C}, h=1.2 \mathrm{~mm}$, and $\eta=0.9$.

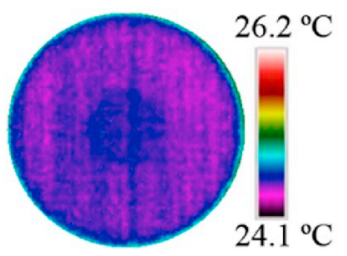

(a) $T_{\mathrm{w}}=25^{\circ} \mathrm{C}, h=1.6 \mathrm{~mm}$

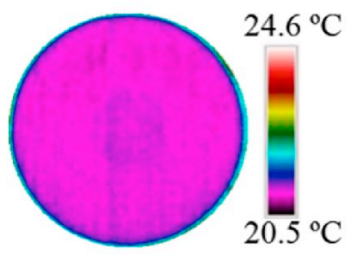

(e) $T_{\mathrm{w}}=20^{\circ} \mathrm{C}, h=1.6 \mathrm{~mm}$



(b) $T_{\mathrm{w}}=25^{\circ} \mathrm{C}, h=1.2 \mathrm{~mm}$



(f) $T_{\mathrm{w}}=20^{\circ} \mathrm{C}, h=1.2 \mathrm{~mm}$

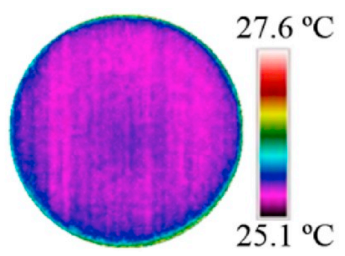

(c) $T_{\mathrm{w}}=25^{\circ} \mathrm{C}, h=0.8 \mathrm{~mm}$

(d) $T_{\mathrm{w}}=25^{\circ} \mathrm{C}, h=0.4 \mathrm{~mm}$



(g) $T_{\mathrm{w}}=20^{\circ} \mathrm{C}, h=0.8 \mathrm{~mm}$

(h) $T_{\mathrm{w}}=20^{\circ} \mathrm{C}, h=0.4 \mathrm{~mm}$

Fig. 5. The infrared images of the ethanol droplet at $\eta=0.9$.

longitudinal and latitudinal directions will happen on the free surface due to the temperature dependence of surface tension. However, compared with the evaporation process in open air condition, the mass transfer resistance will be reduced because the air around the droplet is removed when ethanol droplet evaporates in its pure vapor at $\eta=0.9$. Thus, the droplet evaporation will be enhanced at $\eta=0.9$. In this case, 

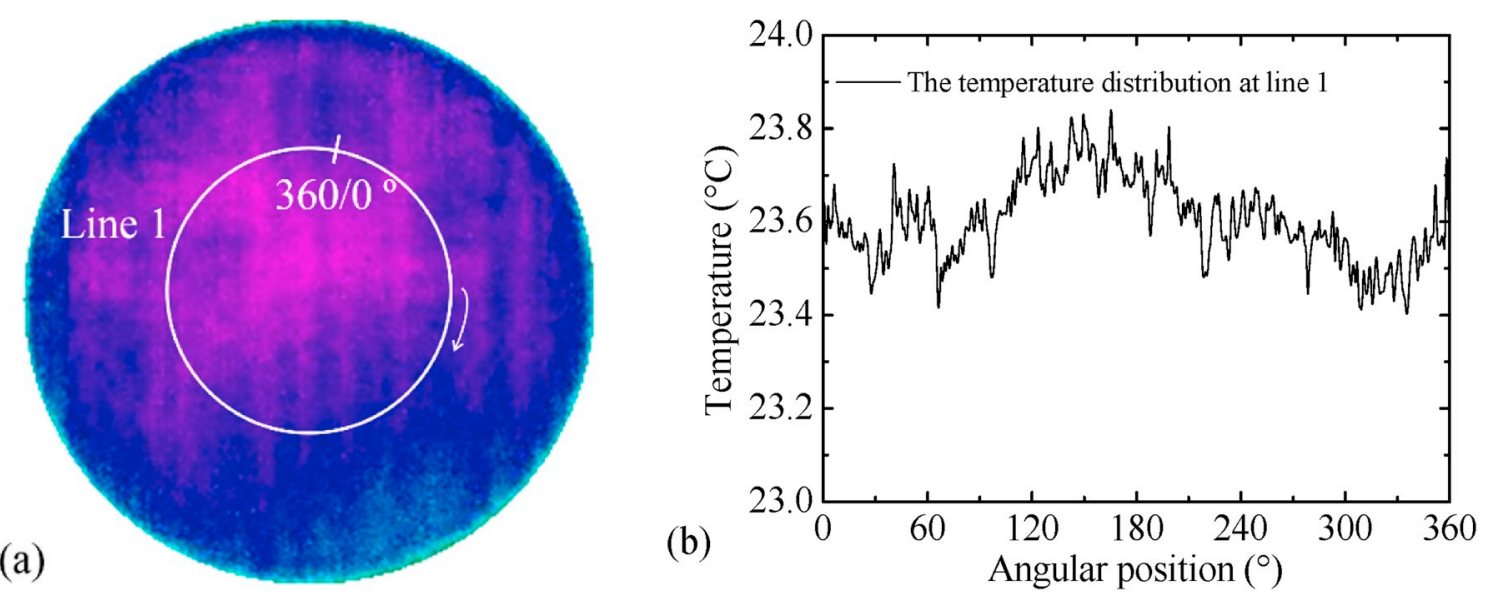


distribution at Line 1 .

the violent evaporation makes the evaporative cooling effect more pronounced. In addition, according to the report of Karapetsas et al. [54], the surface temperature will become uniform when the evaporation rate increases. Therefore, the surface temperature distribution becomes homogeneous when ethanol droplet evaporates at $\eta=0.9$. Meanwhile, the liquid near the three-phase contact line is very close to the substrate, which ensures that the heat dissipation caused by evaporation can be quickly compensated from the substrate. Therefore, there is a large temperature gradient at the three-phase contact line region.

When the vapor pressure ratio is reduced to $\eta=0.6$, the surface temperature distributions of both water and ethanol droplets become diverse. As shown in Fig. 7, the infrared images during water droplet evaporating at $\eta=0.6$ reveal that a ring-shaped high-temperature region emerges on the free surface at a low droplet height, e.g., the position of white dash circle for water droplet in Fig. 7 (d) and (h). More details can be seen in Supplementary Video 1 and 2 . At the same time, like the surface temperature distribution of water droplet at $\eta=0.9$, a warmer region appears near the three-phase contact line. Obviously, the temperature distribution along the latitudinal direction is non-uniform. Since the surface tension is inversely proportional to the temperature, the fluid flows from the high temperature region to the low temperature region. Therefore, the direction of the thermocapillary flow along the latitudinal direction is multiple. In this case, a multi-cell flow pattern appears on the meridian plane, as shown in Fig. 8. This multi-cell flow is similar to the numerical result of Bouchenna et al. [30] on the water droplet evaporation. Indeed, when water droplet evaporates at $\eta=0.6$, evaporation is strong due to the decrease of pressure. The evaporation rate of water droplet increases at least 2.5 times when pressure ratio reduces from 0.9 to 0.6 . Consequently, the evaporative cooling effect increases, which means that the surface temperature will reduce accordingly. The temperature difference between the droplet surface and the substrate becomes large. This vertical temperature difference may be the cause of the multi-cell flow on the meridian plane. Therefore, the ring-shaped temperature distribution appears on the droplet surface. Interestingly, this ring-shaped temperature distribution has not been found in previous similar work. Ward and Duan [36] also investigated the water evaporating into its vapor at low pressures. They found the surface temperature decreases gradually from the contact line to the droplet apex when the vapor pressure is $299.7 \pm 7.1 \mathrm{~Pa}$, which is different from the presented results. The main cause for this difference should be different substrate temperatures. In Ref. [36], the substrate temperature was maintained at $3.56 \pm 0.03{ }^{\circ} \mathrm{C}$, which can ensure that the buoyancy is suppressed. Therefore, the hot water could not reach the droplet surface and the ring-shaped temperature distribution does not appear in their work.

Supplementary video related to this article can be found at

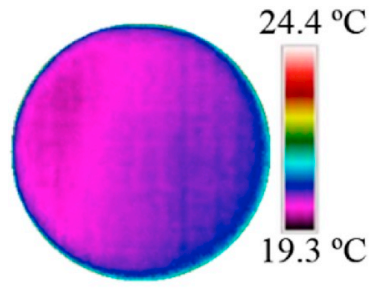

(a) $T_{\mathrm{w}}=25^{\circ} \mathrm{C}, h=1.6 \mathrm{~mm}$

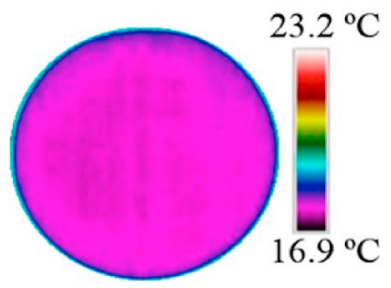

(e) $T_{\mathrm{w}}=20^{\circ} \mathrm{C}, h=1.6 \mathrm{~mm}$

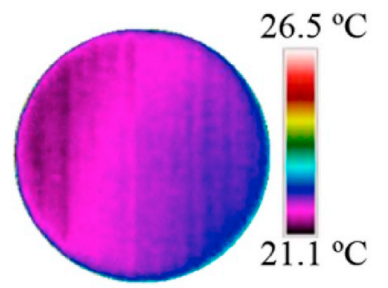

(b) $T_{\mathrm{w}}=25^{\circ} \mathrm{C}, h=1.2 \mathrm{~mm}$

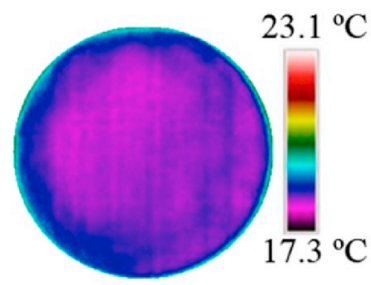

(f) $T_{\mathrm{w}}=20^{\circ} \mathrm{C}, h=1.4 \mathrm{~mm}$



(c) $T_{\mathrm{w}}=25^{\circ} \mathrm{C}, h=0.8 \mathrm{~mm}$

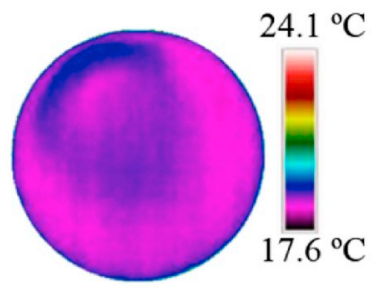

(g) $T_{\mathrm{w}}=20^{\circ} \mathrm{C}, h=0.8 \mathrm{~mm}$

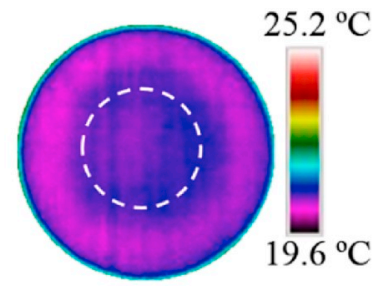

(d) $T_{\mathrm{w}}=25^{\circ} \mathrm{C}, h=0.4 \mathrm{~mm}$

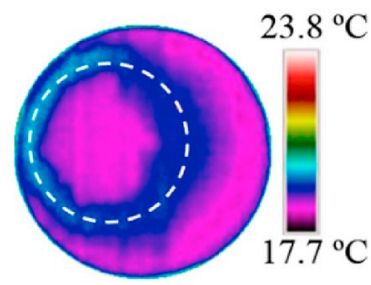

(h) $T_{\mathrm{w}}=20^{\circ} \mathrm{C}, h=0.4 \mathrm{~mm}$

Fig. 7. The infrared images of the water droplet at $\eta=0.6$. The white dash circle is the position of the ring-shaped high-temperature region. 

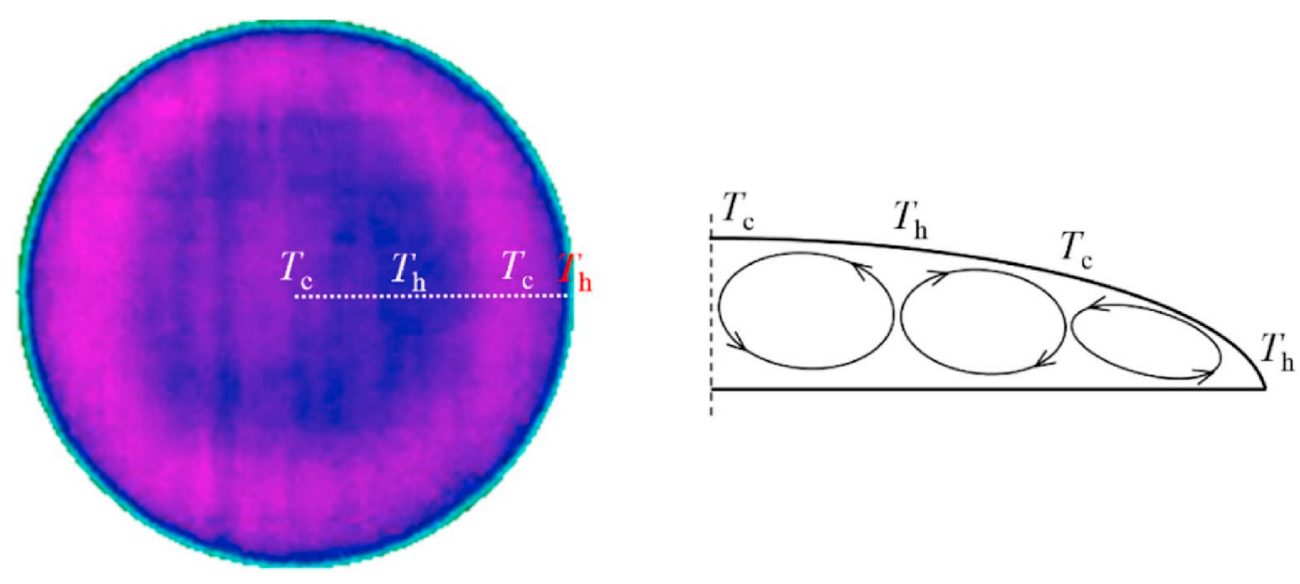

Fig. 8. The schematic of multi-cell flow on a meridian plane.

https://doi.org/10.1016/j.ijthermalsci.2019.106213

Because the thermophysical parameters of ethanol and water are quite different, the thermal flow during ethanol droplet evaporating at $\eta$ $=0.6$ is different from that in water droplet. When $T_{\mathrm{w}}=20^{\circ} \mathrm{C}$, the uniform high-temperature region near the droplet triple line gradually evolves into a gear-like pattern with the decrease of the droplet height, as shown in Fig. 9. This thermal pattern hardly moves along the longitudinal direction (see Supplementary Video 3). As the droplet height decreases, the surface is closer to the substrate. The high temperature region near the contact line will extend. In the three-phase contact line region, a high evaporation flux can be maintained because the evaporating surface is closer to the substrate. The supplement flow takes the cold liquid to the contact line region. The cold liquid may cause the nonuniform temperature distribution in the high temperature region near the contact line. As a result, the gear-like thermal patterns gradually emerged. On the other hand, the heat conduction path near the apex of the droplet is longer than that near the droplet edge. Thereby, the liquid near the apex region is less affected by the substrate temperature. As mentioned before, the evaporation is very severe at low pressures. For instance, when $h=0.4 \mathrm{~mm}$ and $T_{\mathrm{w}}=20^{\circ} \mathrm{C}$, the evaporation rate at $\eta=$ 0.6 is $8.55 \mu \mathrm{l} / \mathrm{min}$, which is more than twice as many as $3.97 \mu \mathrm{l} / \mathrm{min}$ at $\eta$ $=0.9$. Therefore, due to the intensive evaporative cooling effect, a uniform temperature distribution will be maintained near the droplet apex region at $\eta=0.6$ and $T_{\mathrm{w}}=20^{\circ} \mathrm{C}$.

Supplementary video related to this article can be found at https://doi.org/10.1016/j.ijthermalsci.2019.106213

When the substrate temperature increases to $T_{\mathrm{w}}=25^{\circ} \mathrm{C}$, the gearlike thermal patterns also emerge near the triple line with the decrease of droplet height. Different from the result at $T_{\mathrm{w}}=20^{\circ} \mathrm{C}$, the waves of the gear-like pattern are not static. The waves will oscillate along the longitudinal direction. At the same time, a cellular flow appears near the center of the droplet surface, as shown in Fig. 10. When $h$ $=1.2 \mathrm{~mm}$, the cellular flow is first generated near the center of the droplet. Then, it will move to the vicinity of the three-phase contact line and the size gradually shrinks. Finally, the cell will disappear with the oscillation at the three-phase contact line, as shown in Fig. 10(a), and more details can be seen in Supplementary Video 4. The evolution of the cellular flow is periodic. A new cell will appear after the old one disappears at the three-phase contact line. When the pressure ratio is 0.6 , the evaporative cooling effect is remarkable due to the strong surface evaporation. The surface temperature is significantly reduced. Therefore, the temperature difference between the substrate and the free surface increases. When $h=1.2 \mathrm{~mm}$, the temperature difference between the droplet apex and the substrate at $T_{\mathrm{w}}=25^{\circ} \mathrm{C}$ is about $3.5^{\circ} \mathrm{C}$. It is more than twice of that at $T_{\mathrm{w}}=20^{\circ} \mathrm{C}$. Therefore, the increase of vertical temperature difference causes the upward thermal flow, which results in the generation of the cell flow.

Supplementary video related to this article can be found at https://doi.org/10.1016/j.ijthermalsci.2019.106213

When the droplet height decreases to $h=1.0 \mathrm{~mm}$, a combination of the cellular flow and the gear-like pattern will emerge on the droplet surface, as shown in Fig. 10(b). However, the cell size is smaller than that at $h=1.2 \mathrm{~mm}$, and it does not move to the contact line. Meanwhile, the region that gear-like patterns occupied becomes more significant, and the wave oscillation of the gear-like pattern become more obvious (see Supplementary Video 5). As illustrated before, the surface temperature will rise with the decrease of the droplet height. The temperature difference between the substrate and the droplet surface decreases from $3.5^{\circ} \mathrm{C}$ at $h=1.2 \mathrm{~mm}$ to about $2.8^{\circ} \mathrm{C}$ at $h=1.0 \mathrm{~mm}$, which makes the thermal flow in the vertical direction become weakened. Therefore, the cell size decreases. At the same time, the increase of the surface temperature makes the region of the gear-like thermal pattern extend to the center of the droplet surface.

Supplementary video related to this article can be found at https://doi.org/10.1016/j.ijthermalsci.2019.106213

In order to understand the temperature fluctuation on the droplet surface, two temperature monitoring points are set near the contact line and the droplet apex, respectively, as shown in Fig. 10(a). Fig. 11(a) shows the temperature fluctuation at point 1 near the contact line for ethanol droplet evaporating at $\eta=0.6$. It can be found that there is no

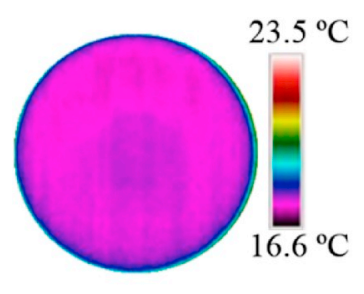

(a) $h=1.6 \mathrm{~mm}$

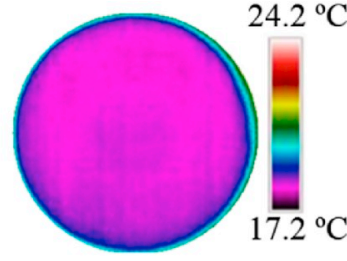

(b) $h=1.2 \mathrm{~mm}$

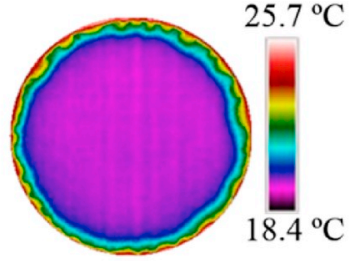

(c) $h=0.8 \mathrm{~mm}$

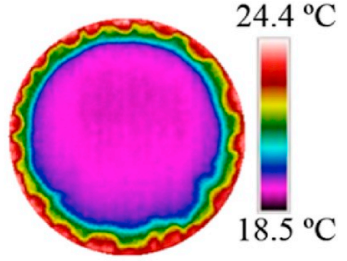

(d) $h=0.4 \mathrm{~mm}$

Fig. 9. The infrared images of the ethanol droplet at $\eta=0.6$ and $T_{\mathrm{w}}=20^{\circ} \mathrm{C}$. 


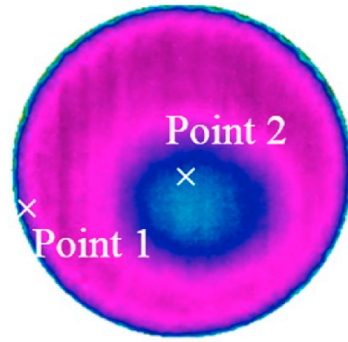

$t_{0} \mathrm{~S}$

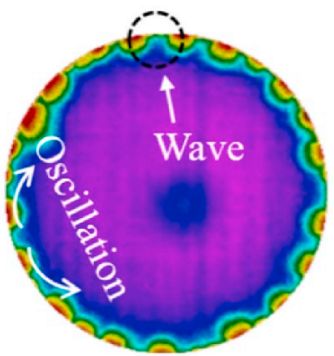

to S

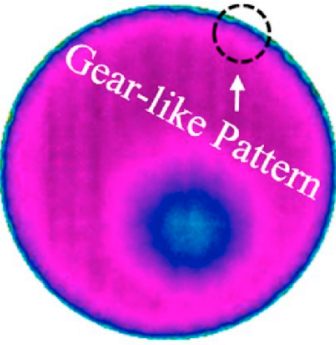

$t_{0}+0.5 \mathrm{~s}$

(a) $h=1.2 \mathrm{~mm}$

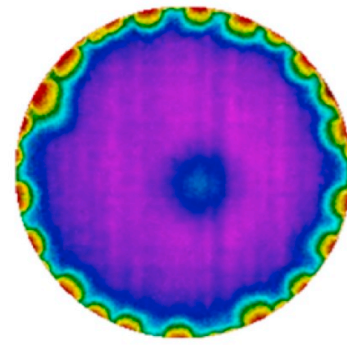

$t_{0}+0.5 \mathrm{~s}$



$t_{0}+4 \mathrm{~s}$



$t_{0}+1 \mathrm{~s}$



$t_{0}+5 \mathrm{~s}$

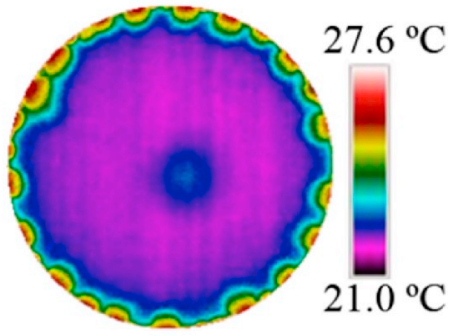

$$
t_{0}+1.5 \mathrm{~s}
$$

(b) $h=1.0 \mathrm{~mm}$

Fig. 10. The infrared images of the ethanol droplet at $\eta=0.6$ and $T_{\mathrm{w}}=25^{\circ} \mathrm{C}$.

fluctuation near the contact line at $T_{\mathrm{w}}=20^{\circ} \mathrm{C}$, even though the gear-like pattern is pronounced at $h=0.4 \mathrm{~mm}$. Nonetheless, the two troughs on the temperature curve at $T_{\mathrm{W}}=25{ }^{\circ} \mathrm{C}$ prove the existence of temperature fluctuation. Fig. 11(b) shows the temperature evolution with time at the monitoring point 2 at the droplet apex at $T_{\mathrm{w}}=25^{\circ} \mathrm{C}$. It can be found that there is an obvious temperature fluctuation at the droplet apex at $h=$ $1.2 \mathrm{~mm}$ and $h=1.0 \mathrm{~mm}$. When ethanol droplet height decreases from $1.2 \mathrm{~mm}$ to $1.0 \mathrm{~mm}$, the apex temperature oscillation amplitude becomes small and the frequency increases. As the drop height decreases, the surface temperature rises, which causes the lowest value of the temperature oscillation to increase. It can be seen from Fig. 11(b), the highest temperatures in the temperature oscillation at the droplet apex for $h=1.0 \mathrm{~mm}$ and $1.2 \mathrm{~mm}$ are almost the same, while the lowest temperature for $h=1.2 \mathrm{~mm}$ is lower than that for $h=1.0 \mathrm{~mm}$. In other words, the oscillation magnitude of the thermal flow rising from the bottom will decrease with the decrease of the droplet height. At the same time, due to the proximity of the droplet surface to the substrate, the upward thermal flow is more likely to reach the droplet surface, and the oscillation frequency is thus increased.

Benefitting from the steady-state evaporation, the evaporation rate $E_{\mathrm{v}}$ can be obtained through the injection rate of the syringe pump. Fig. 12 shows the variations of the evaporation rate of water and ethanol droplets with the droplet height on a heated substrate in its pure vapor at low pressures. Interestingly, the evaporation rate does not change monotonically with the droplet height. It decreases first and then increases with the decrease of the droplet height for water and ethanol droplet evaporating in its vapor. This conclusion is in accordance with the numerical result of Zhang et al. [39].

At $\eta=0.9$, the surface temperature distribution is uniform, and the thermocapillary flow induced by the surface tension gradient is weak. Thus, the evaporation rate is affected by the surface area and the surface temperature of the droplet. When the droplet height is high, almost when $h>1.0 \mathrm{~mm}$ in the present work, the effect of surface temperature on evaporation is less than that of droplet surface. Therefore, owing to the reduction of surface area with the decrease of droplet height, the evaporation rate gradually decreases. As the height decreases further, the surface temperature increases sufficiently, and the heat dissipation generated by liquid evaporation can be rapidly supplemented from the substrate. In this case, the evaporation rate increases with the decrease of the height.

On the other hand, when the pressure ratio is reduced to $\eta=0.6$, the thermal flow also affects the evaporation rate. When the height is low enough, the existence of thermocapillary flow and upward thermal flow will make the warm liquid near the substrate flow to the cold region near the surface. Compared with heat conduction from the substrate to the droplet surface, the thermal flow can quickly compensate for the energy needed for evaporation. Finally, the droplet evaporation will be enhanced. It also can be found that the evaporation rate at $\eta=0.6$ is larger than that at $\eta=0.9$, which demonstrates that the pressure reduction will promote the droplet evaporation. Actually, when the pressure ratio is reduced from 0.9 to 0.6 , the evaporation rates are promoted at least by 1.5 times for ethanol droplet and 2.5 times for water droplet. Moreover, although the evaporation rate of ethanol droplet is higher than that of water droplet, it seems that the influence of pressure reduction on the water droplet evaporation rate is larger than that on the ethanol droplet evaporation rate.

\section{Error analysis}

In order to ensure the accuracy of the evaporation rate measurement, the evaporation rate in Fig. 12 was measured three times for each point. The average value of the total three measurements was used as the representative evaporation rate. The error bars in Fig. 12 is the standard deviation of measured values. It can be calculated by

$s=\sqrt{\frac{1}{n} \sum_{i=1}^{n}\left(E_{v}-\overline{E_{v}}\right)^{2}}$

The largest deviation is $16.5 \%$ for water droplet at $\eta=0.9, T_{\mathrm{w}}=20$ ${ }^{\circ} \mathrm{C}$, and $h=0.6 \mathrm{~mm}$. During the experiment, there are two possible reasons for the deviation of the evaporation rate measurement. On the 


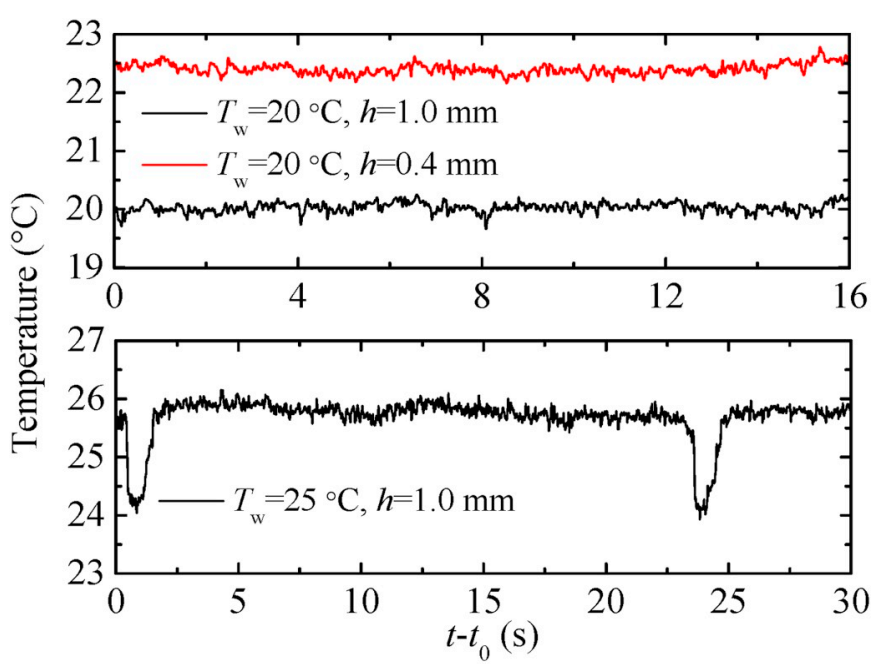

(a) Near the three-phase contact line.

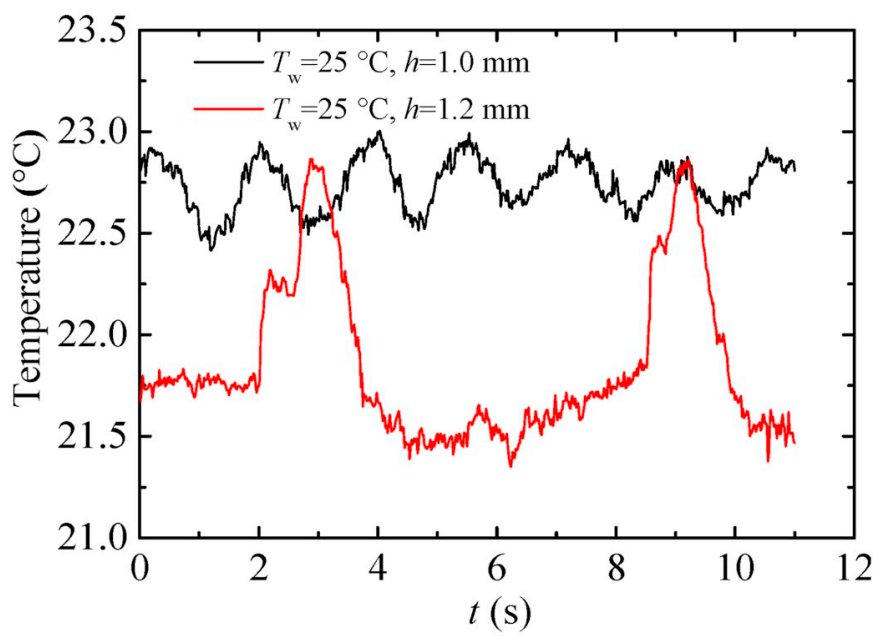

(b) At the droplet apex.

Fig. 11. The temperature fluctuation at the monitoring points.

one hand, the pressure inside the sealed chamber fluctuates within a small range. On the other hand, the deviation of droplet height measurement may exist during the experiment. However, the largest deviation of evaporation rate measurement is $16.5 \%$, which should be acceptable.

\section{Conclusions}

This paper presented a series of experimental results on the evaporation of water and ethanol droplets at low pressures. The evolution of thermal pattern and the variation of evaporation rate are obtained. The following conclusions can be drawn.

(1) For water droplet evaporation, there is a uniform temperature distribution on the free surface due to the intense evaporation at $\eta=0.9$. Only a temperature gradient exists near the three-phase contact line. When the pressure reduced to $\eta=0.6$, the surface temperature distribution becomes non-uniform, the ring-like thermal pattern appears on the free surface.

(2) For ethanol droplet evaporation, the surface temperature distribution is similar to that of water at $\eta=0.9$. Moreover, the change
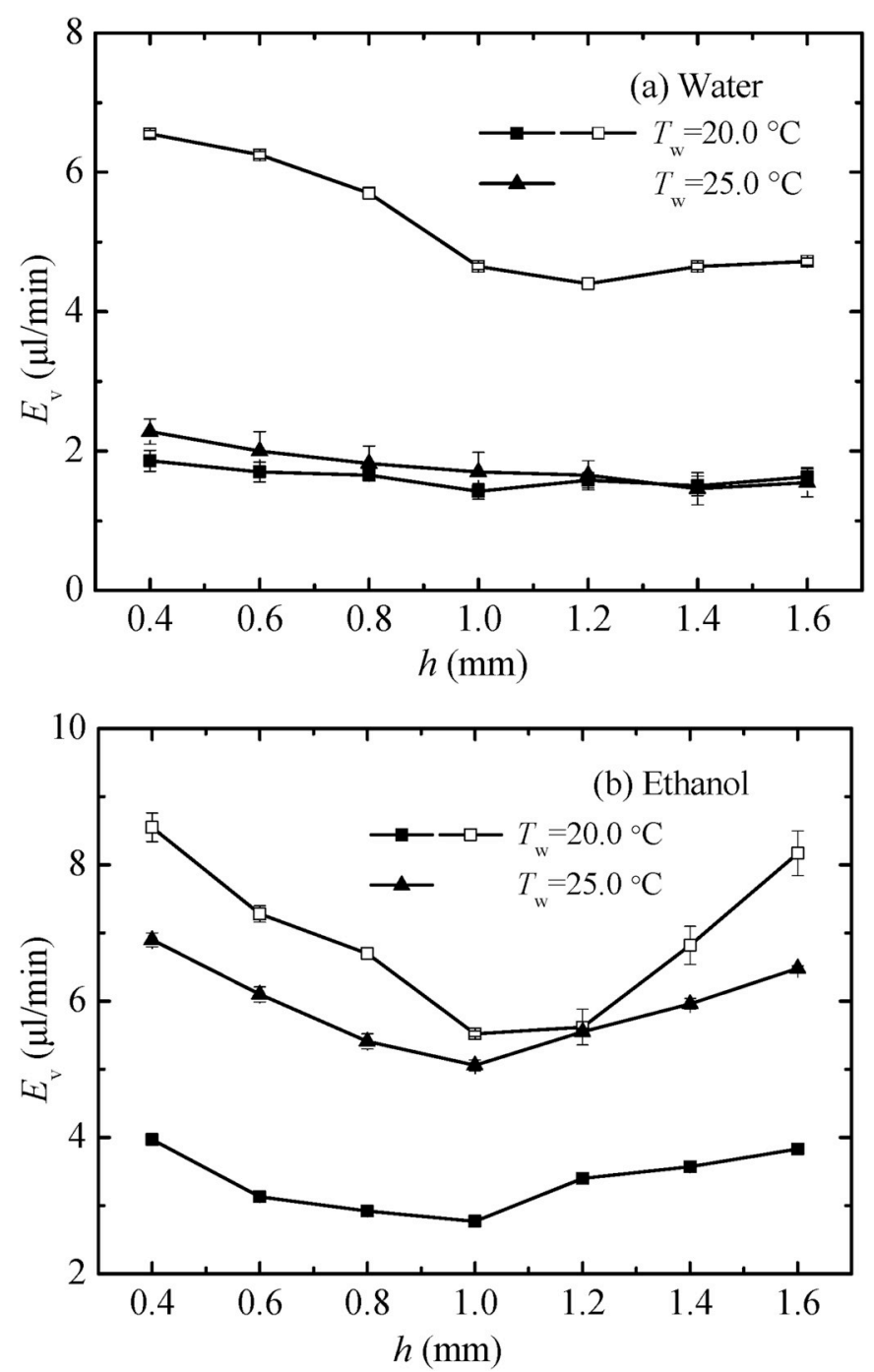

Fig. 12. The evaporation rate of water and ethanol droplets. Solid symbol: $\eta=$ 0.9 , Hollow symbol: $\eta=0.6$.

of vertical temperature difference induced by pressure reduction also influences the temperature distribution on ethanol droplet. However, it is different from that on water droplet. When $\eta=0.6$ and $T_{\mathrm{w}}=20{ }^{\circ} \mathrm{C}$, a stable gear-like pattern appears on ethanol droplet surface at low droplet height. When $\eta=0.6$ and $T_{\mathrm{w}}=25$ ${ }^{\circ} \mathrm{C}$, a cellular flow happens on the ethanol surface. At the same time, the waves of the gear-like pattern will oscillate along the longitudinal direction.

(3) The pressure reduction will promote evaporation. Meanwhile, when the droplet height is high, the evaporation rate decreases with the decrease of droplet height due to the surface area reduction. However, when the droplet height is low, the evaporation rate increases with the droplet height decreasing due to the increase of surface temperature.

\section{Declaration of competing interest}

The authors declared that there is no conflict of interest.

\section{Acknowledgement}

This work is supported by the National Natural Science Foundation of China (Grant No. 11532015, 51776022) and Science and Technology Research Project of Chongqing Education Commission (Grant No. 


\section{KJQN201903305).}

\section{Appendix A. Supplementary data}

Supplementary data to this article can be found online at https://doi. org/10.1016/j.ijthermalsci.2019.106213.

\section{References}

[1] R.D. Deegan, O. Bakajin, T.F. Dupont, Capillary flow as the cause of ring stains from dried liquids, Nature 389 (1997) 827-829.

[2] P. Bhattacharya, A. Samanta, S. Chakraborty, Spray evaporative cooling to achieve ultra fast cooling in runout table, Int. J. Therm. Sci. 48 (2009) 1741-1747.

[3] J. Kim, Spray cooling heat transfer: the state of the art, Int. J. Heat Fluid Flow 28 (2007) 753-767.

[4] D. Vincent, B. Jérôme, S. Eliane, Droplet evaporation study applied to DNA chip manufacturing, Langmuir 21 (2005) 9130-9136.

[5] I.I. Smalyukh, O.V. Zribi, J.C. Butler, O.D. Lavrentovich, G.C. Wong, Structure and dynamics of liquid crystalline pattern formation in drying droplets of DNA, Phys. Rev. Lett. 96 (2006) 177801.

[6] S. Paria, R.G. Chaudhuri, N.N. Jason, Self-assembly of colloidal sulfur particles on a glass surface from evaporating sessile drops: influence of different salts, New J. Chem. 38 (2014) 5943-5951.

[7] Y.-K. Kim, H.-K. Na, S. Ham, D.-H. Min, Mediating ordered assembly of gold nanorods by controlling droplet evaporation modes for surface enhanced Raman scattering, RSC Adv. 4 (2014) 50091-50096.

[8] J. Park, J. Moon, Control of colloidal particle deposit patterns within picoliter droplets ejected by ink-jet printing, Langmuir 22 (2006) 3506-3513.

[9] M. Ren, J. Sweelssen, N. Grossiord, H. Gorter, T.M. Eggenhuisen, R. Andriessen, Inkjet printing technology for OPV applications, J. Imaging Sci. Technol. 56 (2012) 40504-40505, 40504-40501.

[10] K. Sefiane, On the formation of regular patterns from drying droplets and their potential use for bio-medical applications, J. Bionics Eng. 7 (2010) S82-S93.

[11] D. Brutin, B. Sobac, B. Loquet, J. Sampol, Pattern formation in drying drops of blood, J. Fluid Mech. 667 (2011) 85-95.

[12] R.D. Deegan, O. Bakajin, T.F. Dupont, G. Huber, S.R. Nagel, T.A. Witten, Contact line deposits in an evaporating drop, Phys. Rev. E 62 (2000) 756.

[13] E.Y. Gatapova, A.A. Semenov, D.V. Zaitsev, O.A. Kabov, Evaporation of a sessile water drop on a heated surface with controlled wettability, Colloid Surf. APhysicochem. Eng. Asp. 441 (2014) 776-785.

[14] H. Hu, R.G. Larson, Marangoni effect reverses coffee-ring depositions, J. Phys. Chem. B 110 (2006) 7090-7094.

[15] K. Sefiane, J. Moffat, O. Matar, R. Craster, Self-excited hydrothermal waves in evaporating sessile drops, Appl. Phys. Lett. 93 (2008), 074103.

[16] S. Ye, C.-M. Wu, L. Zhang, Y.-R. Li, Q.-S. Liu, Evolution of thermal patterns during steady state evaporation of sessile droplets, Exp. Therm. Fluid Sci. 98 (2018) 712-718.

[17] K. Sefiane, A. Steinchen, R. Moffat, On hydrothermal waves observed during evaporation of sessile droplets, Colloid Surf. A-Physicochem. Eng. Asp. 365 (2010) 95-108.

[18] B. Sobac, D. Brutin, Thermocapillary instabilities in an evaporating drop deposited onto a heated substrate, Phys. Fluids 24 (2012), 032103.

[19] D. Brutin, B. Sobac, F. Rigollet, C. Le Niliot, Infrared visualization of thermal motion inside a sessile drop deposited onto a heated surface, Exp. Therm. Fluid Sci. 35 (2011) 521-530.

[20] K. Sefiane, Y. Fukatani, Y. Takata, J. Kim, Thermal patterns and hydrothermal waves (HTWs) in volatile drops, Langmuir 29 (2013) 9750-9760.

[21] Y. Fukatani, T. Wakui, S. Hussain, M. Kohno, Y. Takata, K. Sefiane, J. Kim, Effect of hydrothermal waves on evaporation distribution during drop evaporation, Heat Transf. Eng. 37 (2016) 729-740.

[22] X. Xu, J. Luo, Marangoni flow in an evaporating water droplet, Appl. Phys. Lett. 91 (2007) 124102.

[23] T.K. Pradhan, P.K. Panigrahi, Thermocapillary convection inside a stationary sessile water droplet on a horizontal surface with an imposed temperature gradient, Exp. Fluid 56 (2015) 178.

[24] K. Gleason, H. Voota, S.A. Putnam, Steady-state droplet evaporation: contact angle influence on the evaporation efficiency, Int. J. Heat Mass Transf. 101 (2016) 418-426.

[25] T. Josyula, Z. Wang, A. Askounis, D. Orejon, S. Harish, Y. Takata, P.S. Mahapatra, A. Pattamatta, Evaporation kinetics of pure water drops: thermal patterns, Marangoni flow, and interfacial temperature difference, Phys. Rev. E 98 (2018), 052804.
[26] P. Chen, S. Harmand, S. Ouenzerfi, J. Schiffler, Marangoni flow induced evaporation enhancement on binary sessile drops, J. Phys. Chem. B 121 (2017) 5824-5834.

[27] R. Picknett, R. Bexon, The evaporation of sessile or pendant drops in still air, J. Colloid Interface Sci. 61 (1977) 336-350.

[28] M. Shanahan, C. Bourges, Effects of evaporation on contact angles on polymer surfaces, Int. J. Adhesion Adhes. 14 (1994) 201-205.

[29] S. Ramos, J. Dias, B. Canut, Drop evaporation on superhydrophobic PTFE surfaces driven by contact line dynamics, J. Colloid Interface Sci. 440 (2015) 133-139.

[30] C. Bouchenna, M.A. Saada, S. Chikh, L. Tadrist, Investigation of thermo-capillary flow inside an evaporating pinned water droplet, Interfacial Phenom. Heat Transf. 3 (2015).

[31] A.O. Semenov, The evaporation of liquid micro-drops on the heated substrate, Thermophysical Basis of Energy Technologies (TBET-2016).—Les Ulis, 2017, in: MATEC Web of Conferences, vol. 92EDP Sciences, 2017, p. 1014.

[32] Y. Fukatani, D. Orejon, Y. Kita, Y. Takata, J. Kim, K. Sefiane, Effect of ambient temperature and relative humidity on interfacial temperature during early stages of drop evaporation, Phys. Rev. E 93 (2016), 043103.

[33] F. Carle, S. Semenov, M. Medale, D. Brutin, Contribution of convective transport to evaporation of sessile droplets: empirical model, Int. J. Therm. Sci. 101 (2016) 35-47.

[34] C. Buffone, Evaporating sessile drops subject to crosswind, Int. J. Therm. Sci. 144 (2019) 1-10.

[35] H. Ghasemi, C. Ward, Energy transport by thermocapillary convection during sessile-water-droplet evaporation, Phys. Rev. Lett. 105 (2010) 136102.

[36] C. Ward, F. Duan, Turbulent transition of thermocapillary flow induced by water evaporation, Phys. Rev. E 69 (2004), 056308.

[37] M.A. Mahmud, B.D. MacDonald, Experimental investigation of interfacial energy transport in an evaporating sessile droplet for evaporative cooling applications, Phys. Rev. E 95 (2017), 012609.

[38] I. Thompson, F. Duan, C. Ward, Absence of Marangoni convection at Marangoni numbers above 27,000 during water evaporation, Phys. Rev. E 80 (2009), 056308.

[39] Y. Zhang, Y.-R. Li, J.-J. Yu, Q.-S. Liu, Three-dimensional numerical simulation on Marangoni convection in a sessile water droplet evaporating in its vapor at low pressure, Microgravity Sci. Technol. (2019) 1-10.

[40] H.Y. Erbil, Evaporation of pure liquid sessile and spherical suspended drops: a review, Adv. Colloid Interface Sci. 170 (2012) 67-86.

[41] D. Brutin, V. Starov, Recent advances in droplet wetting and evaporation, Chem. Soc. Rev. 47 (2018) 558-585.

[42] M. Pack, H. Hu, D.-O. Kim, X. Yang, Y. Sun, Colloidal drop deposition on porous substrates: competition among particle motion, evaporation, and infiltration, Langmuir 31 (2015) 7953.

[43] C. Popiel, J. Wojtkowiak, Simple formulas for thermophysical properties of liquid water for heat transfer calculations (from 0 C to 150 C), Heat Transf. Eng. 19 (1998) 87-101.

[44] V.B. Bekezhanova, O.g.N. Goncharova, I.y.A. Shefer, Analysis of an exact solution of problem of the evaporative convection (Review). Part I. Plane case, Журнал Сибирского федерального университета, Серия «МатеМатика и физика» 11 (2018) 178-190.

[45] R. Tuckermann, S. Bauerecker, H. Cammenga, IR-thermography of evaporating acoustically levitated drops, Int. J. Thermophys. 26 (2005) 1583-1594.

[46] C. Antoine, Thermodynamic vapor pressures: new relation between the pressures and the temperatures (thermodynamique, tensions des vapeurs: novelle relation entre les tensions et les temperatures), C. R. Hebd. Seances Acad. Sci. 107 (1888) 836.

[47] C.L. Yaws, The Yaws Handbook of Vapor Pressure: Antoine Coefficients, Gulf Professional Publishing, 2015.

[48] F. Girard, M.1. Antoni, K. Sefiane, Infrared thermography investigation of an evaporating sessile water droplet on heated substrates, Langmuir 26 (2010) 4576-4580.

[49] F. Girard, M. Antoni, K. Sefiane, On the effect of Marangoni flow on evaporation rates of heated water drops, Langmuir 24 (2008) 9207-9210.

[50] H. Hu, R.G. Larson, Analysis of the effects of Marangoni stresses on the microflow in an evaporating sessile droplet, Langmuir 21 (2005) 3972-3980.

[51] R. Savino, D. Paterna, N. Favaloro, Buoyancy and Marangoni effects in an evaporating drop, J. Thermophys. Heat Transf. 16 (2002) 562-574.

[52] M.A. Kazemi, J.A. Elliott, D.S. Nobes, The influence of container geometry and thermal conductivity on evaporation of water at low pressures, Sci. Rep. 8 (2018) 15121.

[53] X. Zhong, F. Duan, Stable hydrothermal waves at steady state evaporating droplet surface, Sci. Rep. 7 (2017) 16219.

[54] G. Karapetsas, O.K. Matar, P. Valluri, K. Sefiane, Convective rolls and hydrothermal waves in evaporating sessile drops, Langmuir 28 (2012) 11433-11439. 